\title{
METABOLIC SYNDROME OF FREE-LIVING ELDERLY FROM SHARPEVILLE, SOUTH AFRICA: A PROSPECTIVE COHORT STUDY WITH 10-YEAR FOLLOW-UP
}

\author{
W.H. Oldewage-Theron ${ }^{1,2}$, A.A. Egal', C. Grobler ${ }^{3}$
}

\begin{abstract}
Objective: This study aimed to provide evidence on the prevalence of the metabolic factors contributing to Metabolic Syndrome (MetS) among elderly people in South Africa. Design: An ethically approved, cross-sectional survey study conducted in a cohort of an elderly population in 2004 with follow-up in 2014. Setting: An elderly day-care center. Participants: A total of 170 men and women were randomly selected for the baseline survey (2004). Only 105 of the subjects included in the baseline study were available for the follow-up study (2014). The sample consisted of $83.2 \%$ ( $n=89$ ) women and $16.8 \%$ ( $n=16)$ men with a mean \pm SD age of $95.8 \pm 6.2$ and $71.8 \pm 5.7$ years in 2014 and 2004 respectively. Measurements: Dietary intakes (24-hour recall questionnaire) were completed for a period of three non-consecutive days, including one weekend day and two week days. Other measurements included waist circumference (WC), blood pressure and fasting ( $>8$ hours) venous blood samples that were analyzed for total cholesterol (TC), high-density lipoprotein-cholesterol (HDL-C), tryglicerides (TGs) and glucose. The Friedewald formula was used to calculate LDL-C (16). Results: The prevalence of MetS was significantly ( $\mathrm{p}=0.000)$ higher in $2014(63.4 \%)$ compared to 2004 $(48.8 \%)$. The most prominent risk factors were central obesity $(85.9 \%)$, low serum HDL-C (71.0\%) and high serum TG (68.1\%) levels in 2004 compared to central obesity (82.5\%), low serum HDL-C (94.3\%) and hyperglycaemia (48.1\%) in 2014. Conclusions: MetS is highly prevalent and rapidly increasing among these elderly people. A need for identifying preventative and treatment strategies to increase wellness and reduce morbidity has been highlighted by these results..
\end{abstract}

Key words: Metabolic syndrome, elderly, South African, metabolic risk factors, cohort.

\section{Introduction}

Metabolic syndrome (MetS) has become a significant public health issue globally (1). MetS is a complex disorder and includes three or more interconnected metabolic risk factors such as high triglyceride (TG) levels, low high-density lipoprotein-cholesterol (HDL-C) levels, high blood pressure, central obesity and dysglycaemia (1-3). When these risk factors are prevalent simultaneously in individuals, they are in a prothrombotic and pro-inflammatory state that increases the risk of atherosclerotic cardiovascular disease (CVD) and type 2 diabetes (T2DM) $(1,4,5)$ and contribute to all-cause mortality $(1,3)$. Preventable non-communicable diseases (NCDs) such as CVD, T2DM, cancer, and chronic respiratory diseases are responsible for more than 36 million deaths each year, $80 \%$ of which are in

1. Department of Nutritional Sciences, Texas Tech University, 1301 Akron Ave, Lubbock, TX, 79409, USA; 2. Center of Sustainable Livelihoods, Vaal University of Technology, Private Bag X021, Vanderbijlpark, 1900, South Africa; 3. Department of Health Sciences, Vaal University of Technology, Vanderbijlpark, South Africa.

Corresponding Author: Wilna Oldewage-Theron, Professor of Nutrition, Department of Nutritional Sciences, Texas Tech University, 1301 Akron Ave, Lubbock, TX, 79409, USA; Visiting Professor, Center of Sustainable Livelihoods, Vaal University of Technology, Private Bag X021, Vanderbijlpark, 1900, South Africa; Email: wilna.oldewage@ttu.edu low- and middle-income countries (6). It was estimated that $37 \%$ of all deaths in South Africa (SA) were due to NCDs in 2000 (7). A national prevalence rate of $31.8 \%$ for hypertension, $9.5 \%$ diabetes, $23.9 \%$ abnormal high levels of serum total cholesterol (TC), $24.6 \%$ low density lipoprotein-cholesterol (LDL-C), 47.9\% abnormally low HDL-C, and central adiposity observed in $9.8 \%$ of men and $50.8 \%$ of women (8). The prevalence of MetS and the various risk factors increase with age $(1,2)$. Furthermore, higher morbidity and mortality rates for CVD and T2DM have been reported for the elderly diagnosed with MetS due to the physiological changes and various chronic diseases associated with increased age (1). The general prevalence of MetS of up to $60 \%$ among elderly cohorts is high (2), affecting about $40 \%$ and $60 \%$ of Korean aged men and women respectively (1), $40 \%$ of Ecuadorian elderly (9), 33.7\% of Chinese adults (10) and $60 \%$ of Taiwanese elderly (11). Due to the high prevalence of MetS among the elderly and its associated high risk of disease, it is important to know the prevalence and risk factors contributing to MetS for implementing primary prevention strategies. Many studies have focused on the elderly in SA, but the prevalence of MetS among this vulnerable, resource-poor population (12) has not been reported. Therefore, this study aimed to provide evidence on the prevalence of the metabolic factors contributing to 
MetS in a cohort of resource-poor elderly people resident in Sharpeville in the Gauteng Province of SA for the period 2004 to 2014.

\section{Methods}

\section{Study design}

A cross-sectional cohort study with 10 year follow-up design was used. This study was conducted according to the guidelines laid down in the declaration of Helsinki and all procedures involving human subjects were approved by the University of the Witwatersrand's Medical Ethics Committee for Research on Human Beings (M040835) for 2004 and the Vaal University of Technology Senate Research Innovation and Ethics Committee $(20140827 \mathrm{~ms})$ for the 2014 data collection. Due to this elderly community being highly illiterate (12), an information letter and consent form was translated into the Sotho Language and verbally explained to the respondents by trained fieldworkers in 2004 and 2014. The letter included a brief introduction, motivation and purpose of the study. The procedures of the study were explained and confidentiality confirmed by allocating a study number to each of the respondents. Participation was voluntary and participants gave consent by signing the consent form in the form of a fingerprint in the presence of a witness.

\section{Location}

This study was undertaken in the only elderly care center in Sharpeville in the Gauteng Province of SA. Sharpeville is one of the oldest of six townships situated in the Vaal region, an industrial polluted area in the Gauteng Province of SA. Sharpeville has a poverty rate of $43.1 \%$ (13). The center management contacted the researchers in 2004 to undertake the cross-sectional baseline survey to assist them with planning.

\section{Sampling}

Baseline study (2004): Participants were recruited from the then newly established (three months old) Sharpeville Care of the Aged day-care center where freeliving elderly people visited the center on Mondays and Wednesdays. The purpose of attending the day-care center was to provide skills training (sewing, cooking and gardening), religious activities and free breakfast and lunch for food insecure, low-resource elderly (aged $\geq 60$ years). This is the only elderly care center in Sharpeville. A sample size calculator (14) was used and 169 respondents were needed to obtain statistically representative data for the cross-sectional survey for this elderly community (12). A total of 170 men and women were randomly selected for the survey from an alphabetical list of names $(n=350)$ provided by the care center (every second name selected). No exclusion criteria were applied and thus any person who attended the care center and gave informed consent could be selected for the study. Eight fieldworkers, speaking the various indigenous languages of SA, were recruited and trained using a training manual and participatory facilitating methods (12).

Follow-up study (2014): During 2014, the researchers visited the elderly care center again and only 105 of the 169 original respondents of 2004, thus $63.3 \%$ of the original sample, were still voluntarily attending the center and were included in the second investigation. Possible reasons for loss to the follow-up measurements could have been a) mortality during the 10 -year period from baseline to follow-up; b) immobility due to disease or sickness making it impossible for the elderly to attend the care center; or c) elderly moving out of the area and not attending the center any longer. All 105 respondents gave consent to be included in the follow-up study. The same measurements, procedures as well as standardized and validated measuring instruments were used in both 2004 and 2014.

\section{Measurements for both 2004 and 2014}

Dietary intakes were measured by a 24 -hour recall questionnaire completed for a period of three nonconsecutive days, including one weekend day and two week days. Trained fieldworkers used the fourstage, multiple-pass one-on-one interviewing procedure described by Gibson (15). Food models were used to assist the fieldworkers in estimating portion sizes. Dietary intake data were analyzed by a registered dietician using the FoodFinder ${ }^{\circledR}$ version 3 software program, developed by the Medical Research Council and based on the South African food composition tables (16). The mean intake of the three days was calculated.

Waist circumference (WC) was measured at the area halfway between lower rib and iliac crest with a nonstretchable measure tape in a horizontal position around the body (15) by a Registered Dietitian. A registered nursing practitioner measured blood pressure after the respondents had sat quietly for at least 15 minutes with feet on the floor and the right arm supported at heart level. A cuff bladder was used and blood pressure measurements taken with a Tensoval Hartmann ${ }^{\circledR}$ duo control monitor. A second measurement was taken within 10 minutes of the first and the average of the two readings were reported. This monitor uses two methods for determining blood pressure, namely the Korotkoff and the oscillometric methods (17) rendering a more accurate measurement.

The same two nursing practitioners and a haematologist used in 2004 and 2014, drew fasting (>8 hours) venous blood samples in a $7 \mathrm{ml}$ clotted tube, $3 \mathrm{ml}$ glucose (sodium fluoride and oxalate) tube and $5 \mathrm{ml}$ sodium citrate blood between $07 \mathrm{~h} 00$ and $10 \mathrm{~h} 00$, 
after the respondents had been seated for 15 minutes. A vacutainer needle with minimal use of tourniquets was used. The blood was placed on ice, protected from direct sunlight, until separation within two hours of blood collection. Serum and plasma were collected by lowspeed centrifugation (3000 rpm for 30 seconds) at $4^{\circ} \mathrm{C}$ and aliquoted into individual tubes. Serum and plasma were stored at $-80^{\circ} \mathrm{C}$ until analyzes were performed. Standard laboratory protocol was adhered to in order to comply with SANAS accreditation requirement by a heamatologist.

The Konelab 20i random access automated clinical chemistry system was used for TC, HDL-C, TGs and glucose. A coefficient of variation (percent $\mathrm{CV}$ ) between runs of $1.2-2.8 \%$ was obtained for all serum variables. The measuring principles of the Konelab 20i are colorimetric and turbudimetric. The Friedewald formula was used to calculate LDL-C (18).

\section{Statistical analyzes}

All analyses were done using the IBM SPSS, version 23 and $p<0.05$ considered significant for all statistical analyses. Linearity regression was used to test all continuous variables for normality. All the variables were normally distributed, except for the dietary intake variables. All normally distributed variables were reported as means and standard deviations (SDs).

Independent $\mathrm{t}$-tests were performed to determine significant differences in baseline MetS risk factors between the cohort of elderly who were present in 2004 and 2014 and those only present in 2004.

Daily nutrient intakes were reported as medians and interquartile frequencies (IQF) and compared to the Dietary Reference Intakes (DRI) (19), specifically, the Estimated Average Requirement (EAR) values.

The respondents were stratified into two groups based on the International Diabetes Foundation MetS classification for both 2004 and 2014. The MetS group consisted of respondents with a presence of three or more of the following MetS criteria:

- $\mathrm{WC} \geq 80 \mathrm{~cm}$ for women and $\geq 94 \mathrm{~cm}$ for men

- $\mathrm{TRG}>1.7 \mathrm{mmol} / \mathrm{L}(150 \mathrm{mg} / \mathrm{dL})$

- HDL-C $<1.3 \mathrm{mmol} / \mathrm{L}(50 \mathrm{mg} / \mathrm{dL}$ ) for women and $<1.03$ for men

- Blood pressure $\geq 130 / 85 \mathrm{~mm} \mathrm{Hg}$

- Fasting glucose $>5.6 \mathrm{mmol} / \mathrm{L}(100 \mathrm{mg} / \mathrm{dL})(20)$.

The non-MetS group were respondents with or less than two of the metabolic risk factors. Paired t-tests were used to determine the significant differences between baseline (2004) and follow-up (2014). Correlation coefficients were used to examine the association between the study variables $(\mathrm{p}<0.05)$. The students $\mathrm{t}$-test was used to determine the mean difference between continuous variables such age, $\mathrm{WC}$, blood pressure and biochemical values. Thus, the Levene's test for equality of variance was used at $p$-value of $<0.05$. Independent samples t-tests were done to determine significant differences between the men and women at baseline and follow-up. Pearson correlations were done for the nominal data. Only significant results are reported. To understand the predictors of MetS, linear regression (age, systolic and diastolic blood pressure, WC, LDL-C, TRG and serum glucose) was carried out with those dependent variables that had a significant correlation with MetS.

\section{Results}

The independent $\mathrm{t}$-tests showed that there were no significant differences in the baseline MetS risk factors between the cohort of elderly who were present in 2004 and 2014 and those only present in 2004 (HDL-C $p=0.276$, LDL-C $\mathrm{p}=0.818$, TRG $\mathrm{p}=0.647$, serum glucose $\mathrm{p}=0.629$, WC $p=0.294$ ). It is thus assumed that the results were not confounded by those elderly who were not present in 2014.

The sample consisted of $83.2 \% \quad(n=89)$ women and $16.8 \%(\mathrm{n}=16)$ men with a mean \pm SD age of $95.8 \pm 6.2$ and $71.8 \pm 5.7$ years in 2014 respectively. The results in Figure 1 showed that the prevalence of MetS was significantly ( $\mathrm{p}=0.000$ ) higher in 2014 at $63.4 \%$ compared to $48.8 \%$ at baseline (2004). The most prominent risk factors were central obesity $(85.9 \%)$ and low serum HDL-C $(71.0 \%)$ and high serum TRG $(68.1 \%)$ levels at baseline. At followup, the most prominent risk factors were central obesity $(82.5 \%)$, low serum HDL-C $(94.3 \%)$ and hyperglycaemia $(48.1 \%)$. Furthermore, the prevalence of respondents with one and two risk factors decreased at baseline and those with four and five metabolic risk factors progressively increased from baseline to follow-up.

\section{Figure 1}

MetS classification of the respondents at baseline (2004) and follow-up (2014)

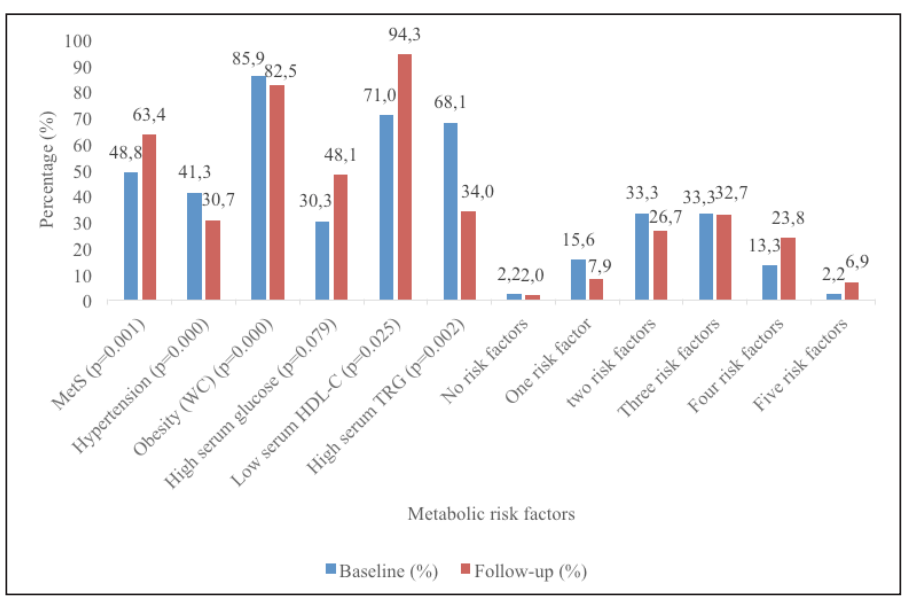

The results in Table 1 indicate a statistically significant $(\mathrm{p}=0.001)$ decrease in HDL-C from a mean \pm SD of $1.04 \pm 0.43$ to $0.84 \pm 0.29 \mathrm{mmol} / \mathrm{L}$ from baseline to followup in the women compared to a statistically significant 
Table 1

Descriptive statistics: anthropometric and biochemical parameters compared across gender

\begin{tabular}{|c|c|c|c|c|c|c|c|c|c|c|}
\hline \multirow[t]{3}{*}{ Variable } & \multirow[t]{3}{*}{ UoM $^{*}$} & \multirow{3}{*}{$\begin{array}{l}\text { Cut-off criteria } \\
\text { for MetS }\end{array}$} & \multicolumn{4}{|c|}{ Women $(n=89,83.2 \%)$} & \multicolumn{4}{|c|}{ Men $(n=16,16.8 \%)$} \\
\hline & & & \multicolumn{2}{|c|}{ Baseline } & \multicolumn{2}{|c|}{ Follow-up } & \multicolumn{2}{|c|}{ Baseline } & \multicolumn{2}{|c|}{ Follow-up } \\
\hline & & & Mean & SD & Mean & SD & Mean & SD & Mean & SD \\
\hline WC & $\mathrm{cm}$ & $\begin{array}{l}<80 \text { (women) } \\
<94 \text { (men) }\end{array}$ & 95.65 & 16.50 & 93.34 & 11.40 & 94.87 & 13.54 & 93.38 & 14.16 \\
\hline Serum glucose & $\mathrm{mmol} / \mathrm{L}$ & $<5.5$ & $6.08^{\mathrm{a}}$ & 3.42 & $6.07^{\mathrm{b}}$ & 2.48 & $4.05^{\mathrm{a}}$ & 1.54 & $4.90^{\mathrm{b}}$ & 1.19 \\
\hline HDL-C & $\mathrm{mmol} / \mathrm{L}$ & $\leq 1.3$ (women) & & & & & & & & \\
\hline$\leq 1.03$ (men) & $1.04 \mathrm{a}$ & 0.43 & $1.04^{\mathrm{a}}$ & 0.43 & $0.84^{\mathrm{a}, \mathrm{b}}$ & 0.29 & 0.89 & 0.43 & $0.64^{b}$ & 0.35 \\
\hline LDL-C & $\mathrm{mmol} / \mathrm{L}$ & $>4.1$ & $2.02^{a}$ & 1.61 & $3.60^{\mathrm{a}}$ & 1.71 & $1.93^{b}$ & 1.57 & $3.17^{\mathrm{b}}$ & 0.91 \\
\hline Serum triglycerides & $\mathrm{mmol} / \mathrm{L}$ & $>1.7$ & 1.42 & 0.72 & 1.56 & 1.12 & 1.70 & 0.77 & 1.60 & 0.91 \\
\hline Systolic blood pressure & $\mathrm{mm} \mathrm{Hg}$ & $<130$ & $137.30^{\mathrm{a}}$ & 26.96 & 137.14 & 29.94 & $154.43^{\mathrm{a}}$ & 30.55 & 151.94 & 29.49 \\
\hline Diastolic blood pressure & $\mathrm{mm} \mathrm{Hg}$ & $<85$ & 83.92 & 18.83 & 82.82 & 22.24 & 87.77 & 30.94 & 80.50 & 17.81 \\
\hline
\end{tabular}

${ }^{*} \mathrm{UoM}=$ Unit of Measure; $\mathrm{a}, \mathrm{b}, \mathrm{c}$ in the same row indicates significant differences at $\mathrm{p}<0.05$

Table 2

Analysis of 24-hour recall: daily mean intakes of the men and women

\begin{tabular}{|c|c|c|c|c|c|c|}
\hline \multirow[t]{3}{*}{ Dietary intake variable } & \multirow{3}{*}{$\begin{array}{l}\text { Unit of } \\
\text { measure }\end{array}$} & \multicolumn{2}{|l|}{ Women $(\mathrm{n}=89,83.2 \%)$} & \multicolumn{2}{|l|}{$\operatorname{Men}(n=16,16.8 \%)$} & \multirow{3}{*}{$\begin{array}{l}\text { DR I (19) / WHO } \\
\text { guidelines (21) }\end{array}$} \\
\hline & & Baseline & Follow-up & Baseline & Follow-up & \\
\hline & & $\begin{array}{l}\text { Median }(25 \text { th; } 75 \text { th } \\
\text { percentile) } \% \text { of TE }\end{array}$ & $\begin{array}{l}\text { Median }(25 \mathrm{th} ; 75 \mathrm{th} \\
\text { percentile) } \% \text { of TE }\end{array}$ & $\begin{array}{l}\text { Median }(25 \mathrm{th} ; 75 \mathrm{th} \\
\text { percentile) } \% \text { of TE }\end{array}$ & $\begin{array}{l}\text { Median }(25 \mathrm{th} ; 75 \mathrm{th} \\
\text { percentile) } \% \text { of TE }\end{array}$ & \\
\hline Total energy (TE) & $\mathrm{kJ}$ & $5425^{\mathrm{a}}(3871 ; 7016)$ & $5155^{\mathrm{a}}(3729 ; 6653)$ & $6025(4206 ; 8819)$ & $4918(2961 ; 6453)$ & $9942(\mathrm{~m}) 6362(\mathrm{w})$ \\
\hline Total protein & $\mathrm{g}$ & $59^{\mathrm{a}}(39 ; 79) 18.3$ & $64^{\mathrm{a}}(40 ; 88) 20.9$ & $69(39 ; 106) 19.7$ & $49(29 ; 101) 19.9$ & 46 \\
\hline Total dietary fat & $\mathrm{g}$ & $32^{\mathrm{a}}(23 ; 47) 27.4$ & $39^{\mathrm{a}}(20 ; 56) 33.0$ & $34^{\mathrm{b}}(16 ; 52) 22.0$ & $46^{\mathrm{b}}(15 ; 63) 33.0$ & $<30 \% \mathrm{TE}$ \\
\hline Dietary cholesterol & $\mathrm{mg}$ & $110.3^{\mathrm{a}}(47.4 ; 224.4)$ & $163.4^{\mathrm{a}}(81.1 ; 268.6)$ & $83.8^{\mathrm{b}}(44.9 ; 293.5)$ & $114.1^{\mathrm{b}}(71.9 ; 349.0)$ & 300 \\
\hline Carbohydrate & $\mathrm{g}$ & $142^{\mathrm{a}}(80 ; 199) 43.9$ & $134^{\mathrm{a}}(91 ; 169) 44.7$ & $130(87 ; 219) 26.8$ & $130(87 ; 163) 42.7$ & 100 \\
\hline Added sugar & G & $20(10 ; 40) 13.0$ & $21(11 ; 36) 4.0$ & $19(8 ; 34) 14.1$ & $17(10 ; 37) 3.9$ & $<10 \% \mathrm{TE}$ \\
\hline Dietary fibre & $\mathrm{g}$ & $11(7 ; 17) 4.1$ & $8(4 ; 13) 3.0$ & $14(4 ; 19) 3.7$ & $7(4 ; 16) 2.8$ & $30(\mathrm{~m}) 21(\mathrm{w})$ \\
\hline Dietary sodium & $\mathrm{mg}$ & $796.1^{\mathrm{a}}(488.4 ; 1227.8)$ & $637.6^{\mathrm{a}}(272.2 ; 997.3)$ & $569.4^{\mathrm{b}}(328.9 ; 1407.6)$ & $565.4^{\mathrm{b}}(229.6 ; 1091.2)$ & 2500 \\
\hline
\end{tabular}

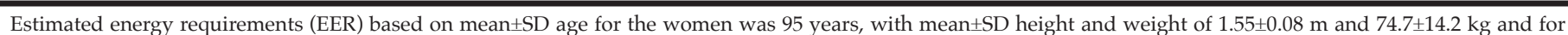

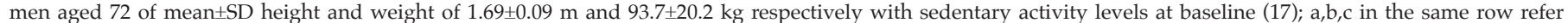

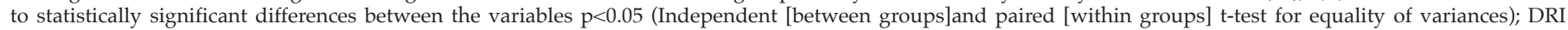

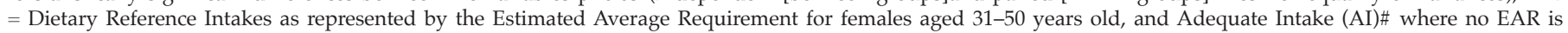
available (17); ${ }^{*} \mathrm{UoM}=$ Unit of Measure

$(p=0.000)$ increase in LDL-C from $2.02 \pm 1.61$ to $3.60 \pm 1.71$ $\mathrm{mmol} / \mathrm{L}$. The men showed a significant $(\mathrm{p}=0.000)$ increase in LDL-C levels from $1.93 \pm 1.57 \mathrm{mmol} / \mathrm{L}$ at baseline to $3.17 \pm 0.91 \mathrm{mmol} / \mathrm{L}$ at follow-up. No other significant changes have been observed. However, a metabolic increase in serum HDL-C and a metabolic decrease in glucose levels were observed in the men at follow-up.

Both men and women had low total energy, dietary fiber, cholesterol and sodium intakes at baseline and follow-up compared to high protein and carbohydrate intakes when compared with the EAR (19). Added sugar intakes were high at baseline, but within the recommended intakes at follow-up. The women showed significantly higher intakes of dietary protein, fat and cholesterol, but significantly lower carbohydrates and sodium at follow-up. The men had significantly higher dietary fat and cholesterol, but reduced sodium intakes at follow-up (Table 2). No significant different dietary intakes were observed between the men and the women.

The Pearson correlation analyses revealed that at baseline MetS was significantly and positively correlated with WC $(r=0.325, p=0.030)$, diastolic blood pressure $(\mathrm{r}=0.219, \mathrm{p}=0.0358)$ and TRG $(\mathrm{r}=0.537, \mathrm{p}=0.000)$ levels and inversely related to HDL-C $(r=-0.423, p=0.004)$ levels at baseline. Furthermore, significant relationships existed between WC and diastolic blood pressure $(r=0.328$, 
$\mathrm{p}=0.003)$ as well as carbohydrate intake with systolic blood pressure $(r=-0.233, r=0.021)$ at baseline. At followup, significant associations were observed between MetS and $\mathrm{WC}(\mathrm{r}=0.428, \mathrm{p}=0.000)$, systolic $(\mathrm{r}=0.271, \mathrm{p}=0.006)$ and diastolic $(\mathrm{r}=0.435, \mathrm{p}=0.000)$ blood pressure, serum HDL-C $(-0.254, \mathrm{p}=0.010)$, TRG $(\mathrm{r}=0.514, \mathrm{p}=0.000)$ and glucose $(0.412, \mathrm{p}=0.000)$ levels as well as added sugar intakes $(\mathrm{r}=0.221, \mathrm{p}=0.028)$. WC showed significant relationships with systolic $(r=0.285, p=0.004)$ and diastolic $(r=0.250$, $\mathrm{p}=0.012)$ blood pressure and serum TRG $(\mathrm{r}=0.230$, $\mathrm{p}=0.020$ ). Further associations were shown between systolic blood pressure with serum LDL-C $(r=0.274$, $\mathrm{p}=0.005$ ) levels.

At baseline, the linear regression analysis carried out on the MetS variables showed that WC, diastolic blood pressure, serum TRG and glucose levels were predictors of MetS at baseline $(\mathrm{R} 2=0.588, \mathrm{p}=0.000, \mathrm{SEE}=0.712)$ and follow-up $(\mathrm{R} 2=0.595, \mathrm{p}=0.000, \mathrm{SEE}=0.752)$ in this community.

\section{Discussion}

Although the concept of MetS is older than five decades, it is receiving more attention now due to its increasing prevalence globally and in Africa as well as its relationship with cardiovascular morbidity and mortality (22). Not much is documented about the prevalence rate of MetS in SA and only a few studies have reported MetS prevalence ranging from an overall $30.2 \%$ in rural women (23) to $60.6 \%$ among colored women in Cape Town (24, 25). These rates indicate a high prevalence of MetS in SA, however, limited information about the prevalence of MetS in the elderly exists for SA. This study thus provides the latest estimate of MetS prevalence among elderly in SA and is, to our knowledge, the first study investigating the prevalence of MetS risk factors among a cohort of elderly over a period of 10 years in SA (2004 to 2014).

According to the International Diabetes Foundation (IDF) definition of MetS (26), the prevalence of MetS among the elderly in this study was $48.8 \%$ in 2004 and it increased to $63.4 \%$ in 2014 , which was consistent with the findings among Taiwanese elderly (11), but higher than elderly in the United States of America (US) (27), Ecuador (9) and Korea (1). Despite the increase in MetS over the ten-year period, no association between MetS and age was established. This was inconsistent with other research findings among adults $(23,28)$, but consistent with the results of de Luis and co-authors for another elderly population (29). The prevalence of MetS was $39.6 \%$ among the women in 2004 and increased to $56.3 \%$ in 2014 compared to $93.4 \%$ and $100.0 \%$ among men respectively in this study. Furthermore, the results of this study were inconsistent with the findings of other studies that reported a higher prevalence of MetS among elderly women compared with men $(1,10)$, but may have been confounded by the small sample of men $(n=16)$. The major differences in MetS risk factors between men and women were dysglycaemia at baseline and follow-up and low HDL-C at follow-up. A significant difference in low serum HDL-C levels for gender was also observed in Chinese elderly (10).

A shift in MetS risk factors was observed among the respondents at follow-up. Furthermore, significant associations existed among the various MetS risk factors at baseline and follow-up. At baseline, 15.6\%, 33.3\%, $33.3 \%, 13.3 \%$ and $2.2 \%$ had one, two, three, four or five MetS risk factors respectively. This changed at follow-up with fewer elderly persons with one $(7.9 \%)$, two $(26.7 \%)$ and three $(32.7 \%)$ risk factors, but significantly more with four $(23.8 \%)$ and five $(6.9 \%)$ risk factors at followup. The predictors of MetS at both baseline and followup for this study was WC, diastolic blood pressure, and serum HDL-C and TRG levels. Interestingly, low serum HDL-C was the most prominent risk factor for MetS among these elderly cohort with a prevalence of $94.3 \%$ followed by obesity $(82.5 \%)$ at follow-up, but at baseline these were reversed with obesity (WC) being the most prominent risk factor with a prevalence of $85.9 \%$ compared to $71.0 \%$ for serum HDL-C. These results were consistent with another black population in SA (30). However, among Korean elderly, hypertension was the most prominent risk factor, followed by HDL-C (1). The prevalence of abnormally low HDL-C levels in this study at baseline and follow-up was much higher than the national prevalence rate of $47.9 \%$ (8). This result was also consistent with studies from Botswana, Nigeria, Cameroon and Cotonou where it was observed that reduced HDL-C contributed frequently to dyslipidaemia in Africans with MetS (22). A significant difference in HDL-C was observed.

Despite the poor socio-economic status of these elderly (12) and although prevalence decreased significantly $(p=0.000)$ over the 10 years' cohort study, the prevalence of central obesity $(>80 \%)$, one of the major factors contributing to MetS (22), was much higher than the national prevalence rate (8) and the global prevalence of $20 \%$ among the adult population (28). In recent years, poverty and food insecurity have been linked to obesity and its associated NCDs (31). This paradoxical condition is a result of a poor quality diet consisting of mainly energy-dense, low nutrient food items containing too much fat, salt and sugar that lead to the double burden of disease, thus the co-existence of over- (obesity and NCDs) and under- (micronutrient deficiencies) nutrition, often found in countries undergoing the nutrition transition $(32,33)$ such as SA. The dietary intake analyzes of the elderly in our study showed an inadequate diet, as the median energy intakes were consistently low, with even lower intakes at follow-up when compared to the EER. Furthermore, the dietary intake of the men and women in this study showed low intakes of dietary fat, fiber and cholesterol. Although the median protein and carbohydrate intakes were high when compared to the EAR, the percentage it contributed to TE was within the guidelines for a balanced and healthy diet. 
Dietary carbohydrate is strongly related to serum glucose levels and lipid metabolism. A high carbohydrate intake can increase serum TGs and possibly decrease HDL-C levels (34). Although the intakes of carbohydrates were at least 30\% higher than the EAR in 2004 and 2014, no significant relationship between carbohydrate intake and serum lipid could be established. However, the relatively high carbohydrate intakes could have contributed to the prevalence of metabolic dyslipidaemia and dysglycaemia found among the elderly men and women in our study. At follow-up, dietary intakes of added sugar was significantly correlated with MetS. This may have contributed to the higher prevalence of dysglycaemia at follow-up. Dietary fiber intakes were considerably lower than recommended and both the men and women consumed less dietary fiber at follow-up, however this was not significant. Dietary fiber, specifically whole grain fiber, is important for cardio-metabolic health due to its proven lowering effect of serum TG and LDL-C (35); however, this association could not be confirmed for this study. However, a lower dietary fiber intake and significantly $(\mathrm{p}=0.025)$ higher prevalence of low HDL-C levels were observed at follow-up.

In this study the prevalence of hypertension was $41.3 \%$ at baseline and decreased significantly $(p=0.000)$ to a prevalence of $30.7 \%$ at follow-up. This was much higher than the national prevalence of hypertension of $10.2 \%$ (8). Although a large percentage of the elderly had hypertension, the dietary sodium intake was low. In addition, no association between sodium intake and hypertension could be established. This was consistent with a study undertaken in Ecuadorian elderly (9). Type 2 diabetes is no longer a rare condition in Africa and accounts for almost $90 \%$ of all the cases of diabetes mellitus. It is well known that type 2 diabetes increases the probability of developing MetS. A review of MetS in Africa has found that it ranks low in terms of the contributing factors to MetS (22). Similarly, in our study, dysglycaemia ranked the lowest of all the risk factors at baseline with a prevalence of $30.3 \%$. Although the prevalence of dysglycaemia increased to $48.1 \%$ at followup, this was not significant $(\mathrm{p}=0.079$ ).

This study contributes to the paucity of data about the prevalence of MetS among the elderly in SA, but had a number of limitations. The first limitation was that this was a cross-sectional survey in 2004 with a 10 -year follow-up in the same elderly that were participating in the 2004 baseline and still attending the care center (cohort) in 2014, lacking the ability to infer causal relationships. Another limitation was the small sample size due to $36.7 \%(n=64)$ of the respondents in the original sample in 2004 were not available for measurements in 2014. Furthermore, the respondents were selected from the only elderly care center from one township only. This is thus not a representative sample and the results cannot be generalized. Caution should also be used in interpreting the results of the men due to the small sample size. However, as an exploratory study, the results revealed issues and actions needed for future research. Although different MetS criteria are used in different studies and comparing results can thus be a limitation (22), the information generated are still informative about the burden of MetS among the elderly South African population.

\section{Conclusion and recommendations}

This study indicates that MetS is highly prevalent and rapidly increasing among these poor black elderly people residing in urban Sharpeville, SA. Although the prevalence of MetS and its various risk factors increased significantly from baseline to follow-up, no significant association between MetS and age was established in this elderly community. MetS is associated with NCD morbidity and mortality and the high MetS burden thus underscores the need for prevention and treatment strategies to increase wellness and reduce morbidity in the elderly of SA. Health-promoting behaviors should be encouraged among the elderly to prevent the increase in prevalence of MetS risk factors with age. Dietary interventions should include strategies to improve dietary intakes and to normalize dyslipidaemia and dysglycaemia, reduce hypertension and improve weight status. Furthermore, policy makers and local health authorities should design and implement regular screening campaigns to identify and treat individual risk factors as early as possible to avoid progression to MetS. This should reduce expenditure on both capital and human health resources in the country.

Acknowledgements: The authors acknowledge the National Research Foundation (NRF) and the Vaal University of Technology for funding, as well as the women participating in the study and the fieldworkers for their assistance.

Financial support: This research has been funded by the National Research Foundation (NRF) and the grant numbers are nr $62501 \& 81280$. The sponsors had no role in design and conduct of the study; in the data collection, analysis, and interpretation of data; in the preparation of the manuscript; or in the review or approval of the manuscript.

\section{Conflict of interest: The authors declared that they had no conflict of interests.}

Ethical standard: This study was conducted according to the guidelines laid down in the declaration of Helsinki and all procedures involving human subjects were approved by the University of the Witwatersrand's Medical Ethics Committee for Research on Human Beings (M040835) for 2004 and the Vaal University of Technology Senate Research Innovation and Ethics Committee ( $20140827 \mathrm{~ms})$ for the 2014 data collection. Fingerprint informed consent was obtained from all the subjects.

\section{References}

1. Kim S, So WY. Prevalence and correlates of metabolic syndrome and its components in elderly Korean adults. Exp dys 2016;84:107-112.

2. Georgousopoulou EN, Naumovski N, Mellor DD, et al. Association between siesta (daytime sleep), dietary patterns and the presence of metabolic syndrome in elderly living in Mediterranean area (MEDIS study): The moderating effect of gender. J Nutr Health Aging 2016;20:1- 7 .

3. Appelhans BM, Baylin A, Huang MH, et al. Beverage Intake and Metabolic Syndrome Risk Over 14 Years: The Study of Women's Health Across the Nation. J Acad Nutr Diet 2017;117(4):554-562.

4. Cicero AFG, Colletti A. Role of phytochemicals in the management of metabolic syndrome. Phytomedicine 2016;23:1134-1144.

5. López A, Peréz-Rodrigo R. Nutrition and the metabolic syndrome. Nutr clín diet hosp 2012;32(3):92-97. 
6. World Health Organization (WHO). New WHO report: Deaths from noncommunicable diseases on the rise, with developing world hit hardest. 2011. http: / / www.who.int/mediacentre/news / releases / 2011/ncds_20110427/ en/. Accessed 25 October 2017.

7. Bradshaw D, Groenewald P, Laubscher R, et al. Initial burden of disease estimates for South Africa, 2000. S Afr Med J 2003;93(9):682-688

8. Shisana O, Labadarios D, Rehle T, et al. South African National Health and Nutrition Examination Survey (SANHANES-1). 2014. HSRC Press, Cape Town.

9. Sempértegui F, Estrella B, Tucker KLO, et al. Metabolic syndrome in elderly living in marginal peri-urban communities in Quito, Ecuador. Public Health Nutr 2011;14(5):758-767.

10. Yang F. Prevalence of metabolic syndrome in the middle-aged and older Chinese population. Int J Diabetes Dev Ctries 2017;37(2):176-182.

11. Wu TT, Chen IJ, Cho SL, et al. The relationship between health-promoting behaviors and metabolic syndrome in community-dwelling older adults. Biol Res Nurs 2016;18(5):549-557.

12. Oldewage-Theron WH, Salami L, Zotor FB, et al. Health status of an elderly population in Sharpeville, South Africa. Health SA Gesondheid 2008;13(3):317.

13. Sekatane MB. An application of different methodologies for measuring poverty in Sharpeville township. Medit J Soc Sc 2013;4(14). http: / / www. mcser.org/journal/index.php/mjss/article/view/1577. Accessed 08 January 2018.

14. The Survey System. Sample size calculator. http://www.surveysystem.com/ ssformu.htm. Accessed 08 January 2018.

15. Gibson RS. Principles of nutritional assessment, 2nd edn. 2005. Oxford University Press, New York.

16. Langenhoven ML, Kruger ML, Gouws E, et al. Food composition tables. Medical Research Council, Parow, 1991.

17. HARTMANN in South Africa. Tensoval blood pressure monitors. 2017 Available at: http://za.hartmann.info/tensoval_monitor.php. Accessed 24 October 2017.

18. Warnick GR, Knopp RH, Fitzpatrick V, et al. Estimating low-density lipoprotein cholesterol by the Friedewald equation is adequate for classifying patients on the basis of nationally recommended cut points. Clin chem 1990;36:15-19.

19. Institute of Medicine (IoM), Food and Nutrition Board. Dietary Reference Intakes. 2003. National Academy Press, Washington DC.

20. Grundy SM, Cleeman JI, Daniels SR, et al. Diagnosis and management of the metabolic syndrome: an American Heart Association/National Heart, Lung and Blood Institute Scientific Statement. Circulation 2005;112:2735-2752.

21. Food and Agricultural Organization (FAO) and World Health Organization (WHO). Fats and fatty acids in human nutrition. Report of an expert consultation. 2010. FAO, Geneva.

22. Okafor CI. The metabolic syndrome in Africa: current trends. Indian J Endocrinol Metab 2012;16(1):56-66.

23. Motala AA, Esterhuizen T, Pirie FJ, et al. The prevalence of metabolic syndrome and determination of the optimal waist circumference cut-of points in a rural South African community. Diabetes Care 2011;34:1032-1037.

24. Erasmus RT, Soita DJ, Hassan MS, et al. High prevalence of diabetes mellitus and metabolic syndrome in a South African coloured population: Baseline data of a study in Bellville, Cape Town. S Afr Med J 2012;102(11):851-844.

25. Kruger MJ, Nell T. The prevalence of the metabolic syndrome in a farm worker community in the Boland district, South Africa. BMC Public Health 2017;17:61.

26. International Diabetes Foundation (IDF) Clinical Guidelines Task Force Global guideline for type 2 diabetes: recommendations for standard comprehensive, and minimal care. Diabet Med 2006;23(6):579-593.

27. Ford ES. Risks for all-cause mortality, cardiovascular disease, and diabetes associated with the metabolic syndrome. Diabetes care 2005;28(7):1769-1778.

28. Lechleitner M. Obesity and the metabolic syndrome - a mini-review. Gerontology 2008;54(5):253-259.

29. De Luis DA, Lopez Mongil R, Gonzalez Sagrado M, et al. Prevalence of metabolic syndrome with International Diabetres Federation Criteria and ATP III Program in patients of 65 years of age or older. J Nutr, Health Aging 2010;14(5):400-404.

30. Peer N, Steyn K, Levitt N. Differential obesity indices identify the metabolic syndrome in black men and women inCape Town: the CRISBA study. J Public Health 2015;38(1):175-82.

31. Tanumihardjo S, Anderson C, Kaufer-Horwitz M, et al. Poverty, obesity, and malnutrition: an international perspective recognizing the paradox. J Am Diet Assoc 2007;107:1966-1972.

32. Olson C. Nutrition and health outcomes associated with food insecurity and hunger. J Nutr 1999;129,Suppl. 2:S521-S524.

33. Haddad L, Hawkes C, Webb P, et al. A new global research agenda for food. Nature 2016;540:30-32.

34. Riccardi G, Rivellese AA. Dietary treatment of the metabolic syndrome - the optimal diet. Br J Nutr 2000;83,Suppl.1:S143-S148.

35. Mozzafarian D, Appel LJ, van Horn L. Components of a cardioprotective diet. New insights. Circulation 2013;123:2870-2891. 